\title{
AERIAL DISPERSAL BEHAVIOR OF TWO ORB WEAVING SPIDERS
}

\author{
BY WAYNE W. TOLBER'T* \\ Graduate Program in Ecology \\ University of Tennessee \\ Knoxville, Tennessee 37916
}

\section{Introduction}

Aerial dispersal, the transport of spiders from place to place by wind and/or convection currents, has been recognized as a feature of spider behavior since the time of Aristotle (Duffey, 1956). Many natural historians and arachnologists have observed and briefly commented on this phenomenon (Emerton, 1908; Bristowe, 1939; Gertsch, 1949; Nishiki, 1966; and Kaston, 1972), and a few studies have been devoted to the environmental conditions associated with the general phenomenon of spider dispersal.

Most studies and observations have been made of mass migrations of several species of spiders, particularly migrations occurring during the winter months (Bristowe, 1939). Duffey (1956) determined that temperature, population density, and stages of the breeding cycle are associated with mass aerial migrations of several species of Linyphiidae. Van Wingerden and Vugts (1974) produced results similar to Duffey's for one lingphiid species, Erigone artica (White).

Richter $(1970,1971)$ has studied in the laboratory some microclimatic factors which influence aerial dispersal in eight species of Pardosa wolf spiders. Richter (1970) related the frequency of aeronautic behavior of each species to the abundance and stability and that species' preferred habitat.

The purposes of this study are to describe the aerial dispersal behavior of Argiope trifasciata (Forskal), to compare behavioral elements of this species with a sympatric population of the congener, A. aurantia (Lucas), and to determine, under actual field conditions, the major physical parameters which influence these behaviors. Factors influencing emergence from the egg sac are discussed elsewhere (Tolbert, 1976, in preparation).

*present address - Science Applications, Inc.

P. O. Box 843

Oak Ridge, Tennessee 37830

Manuscript received by the editor May 27, 1977 


\section{Methods}

This study was conducted in April and May 1975, in a two hectare overgrown pasture in Loudon County, Tennessee; a complete description of the study area is reported elsewhere (Tolbert, 1976). The study area is 3.2 kilometers ( 2 miles), west of Glendale community. Spiderlings of two orb weaving spider species, Argiope trifasciata and Argiope aurantia, were observed after emergence from more than 50 egg sacs. The spiderlings from egg sacs were monitored for dispersal and related activities during daylight hours. Spider body temperatures were estimated by the use of a thermocouple junction and associated cylindrical solder model of the same dimensions as a first instar spiderling $(0.5 \mathrm{~mm} \times 1.5 \mathrm{~mm})$. Direct readout of model temperatures at dispersal height were recorded on an Esterline-Angus Continuously Recording Potentiometer. Wind speeds at dispersal height were measured with a Rimco miniature cup anemometer, stall speed $0.25 \mathrm{~m} / \mathrm{sec}$.

\section{Behavior Prior to Dispersal}

Unlike Argiope aurantia spiderlings, which emerge from an egg sac over a period of several days or weeks (Tolbert, 1976), Argiope trifasciata emerged in mass during the study period of April and May 1975. All spiderlings emerged from any given egg sac within a single day, usually within a period of one to two hours. This was confirmed by cutting open egg sacs from which spiderlings had recently emerged and checking for spiderlings that were left. An ethogram which summarizes the findings of this study on Argiope spp. dispersal behavior is depicted in Figure 1. Individuals quickly constructed a communal tangle or communal web, which is a meshwork of interlocking threads, by laying down draglines. Division of labor was not observed; each spiderling simply contributed a small amount of silk to the tangle. Spiderlings observed in 1975 resided on such tangles for several days $(\overline{\mathrm{x}} \pm S . E .=3.5 \pm 0.52$ days) before dispersing. Valerio (1975) reports that the common house spider Achaeranea tepidorium (C. L. Koch), also spends three to four days in dense clusters on the maternal web before dispersing aerially. Communal tangle formation by Argiope aurantia was less common. In the four instances where communal tangles were constructed by $A$. aurantia, the egg sacs had fallen to the substrate. Possibly a differing microclimate near the 


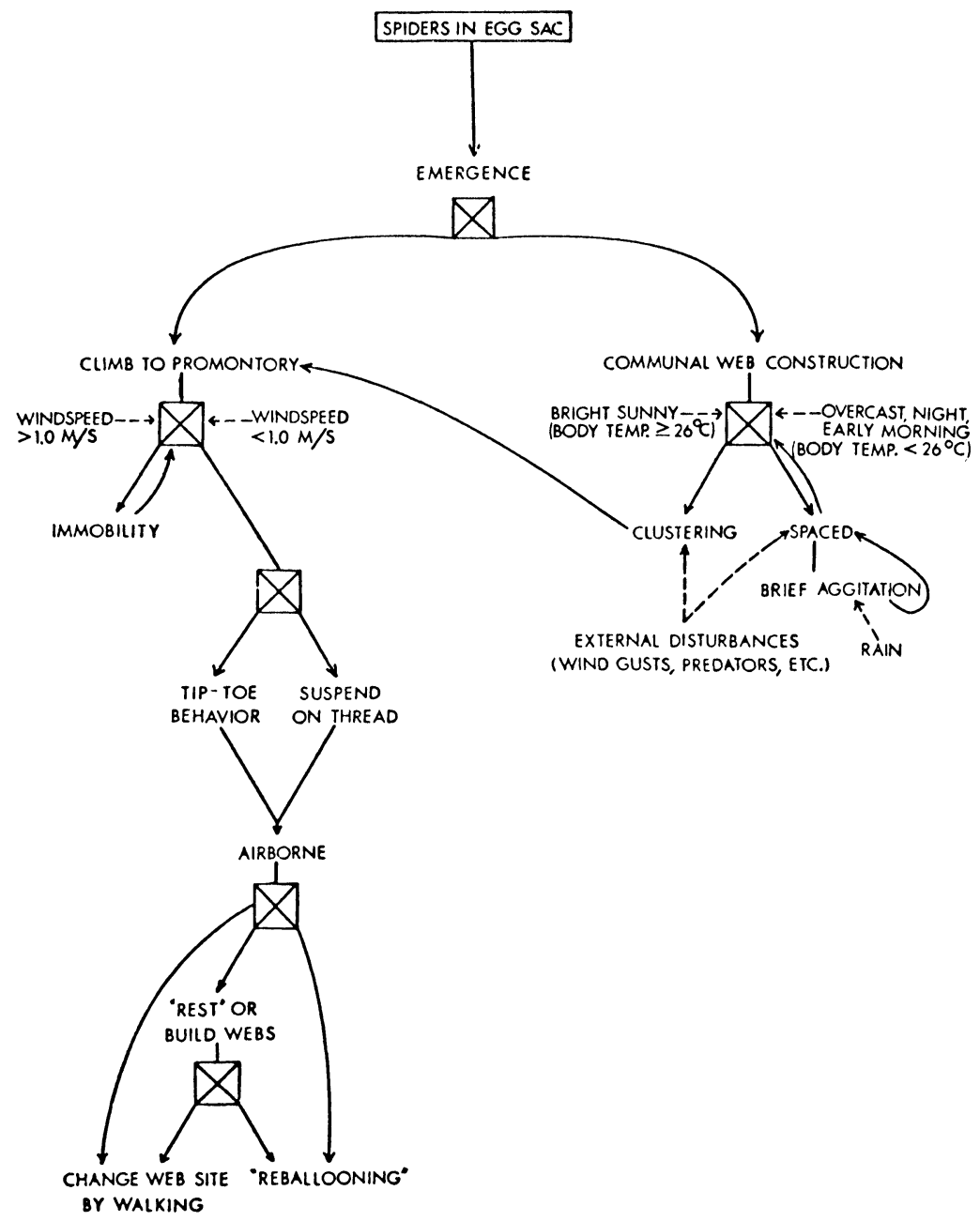

Figure 1. An ethogram of Argiope spp. dispersal behavior. 
ground as demonstrated by Geiger (1965) influences communal tangle formation. Spiderlings emerging high in the vegetation experience greater exposure to wind which might stimulate ballooning (discussed below). Argiope aurantia locate egg sacs higher in the vegetation than $A$. trifasciata. In 1974-1975 and 1975-1976 the means and standard errors of $A$. aurantia egg sac heights were $0.91 \pm 0.11$ and $1.10 \pm 0.13 \mathrm{~m}$, respectively (Tolbert, 1976). Argiope trifasciata egg sacs by comparison, were $0.30 \pm 0.04 \mathrm{~m}$ in $1975-1976$ (Tolbert, 1976).

Spiderlings on a communal tangle were tolerant of one another at all times and readily accepted conspecifics from different egg sacs. Several such "transplants" were made during the spring of 1975 with spiderlings from one egg sac transferred to the communal tangle of spiderlings from a different egg sac. After a brief flurry of activity produced by the arrival of the transplants, activity decreased to levels noted before the introductions.

At night, early in the morning, and on overcast days Argiope trifasciata spiderlings maintained individual spacing of several times their own body length while on the communal tangle (Figure 2). If disturbed by predators, wind gusts, or rain, spiderlings became agitated but quickly resumed a quiescent attitude if their body temperatures were less than $26^{\circ} \mathrm{C}$. On the other hand, if exposed to full sunlight individuals clustered closely together on the communal tangle (Figure 3). If cues were not present for dispersal, the spiderlings remained clustered until after nightfall before spacing out. Though not timed, clustering appeared to take less than a minute. A longer period was required for clustering if the group was partially shaded. The exact cue or clues producing clustering are not known, but clustering occurred only after full exposure to bright sunlight. Air temperatures, spiderling body temperatures, light levels, and perhaps other factors which might provide the required stimuli for clustering all change at this time. More experimentation is needed for elucidation of this problem.

When Argiope trifasciata spiderlings are clustered and their body temperatures equalled or exceeded $26^{\circ} \mathrm{C}$ they were susceptible to dispersal. As indicated in Figure 4, dispersal ceased below $26^{\circ} \mathrm{C}$ and the preferred temperature range for dispersal was between $33^{\circ}$ and $38^{\circ} \mathrm{C}$. Ninety-two percent of all $A$. trifasciata spiderlings became airborne or "ballooned" when their estimated body temperatures were between $33^{\circ}$ and $38^{\circ} \mathrm{C}$. Argiope aurantia also dispersed 


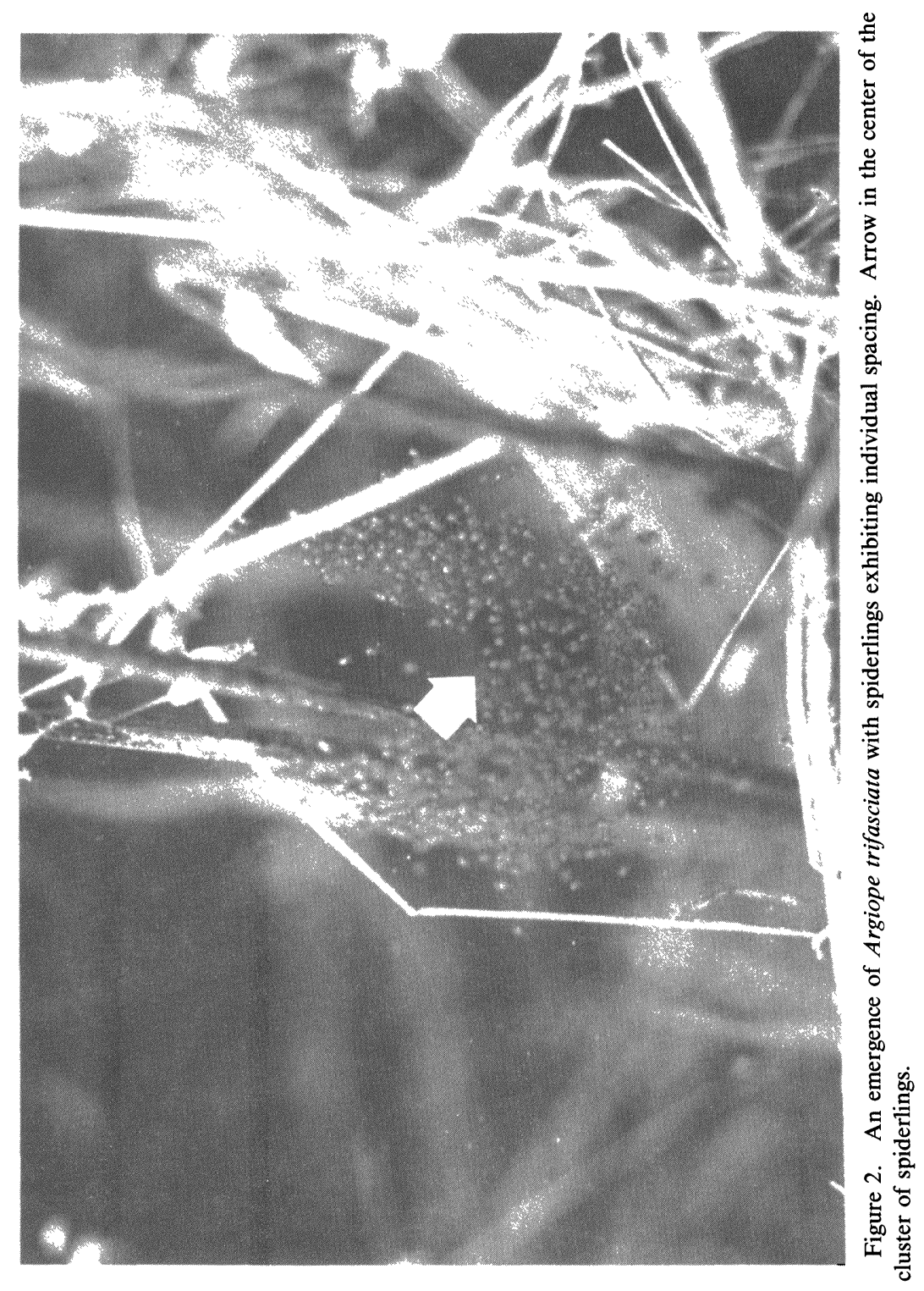




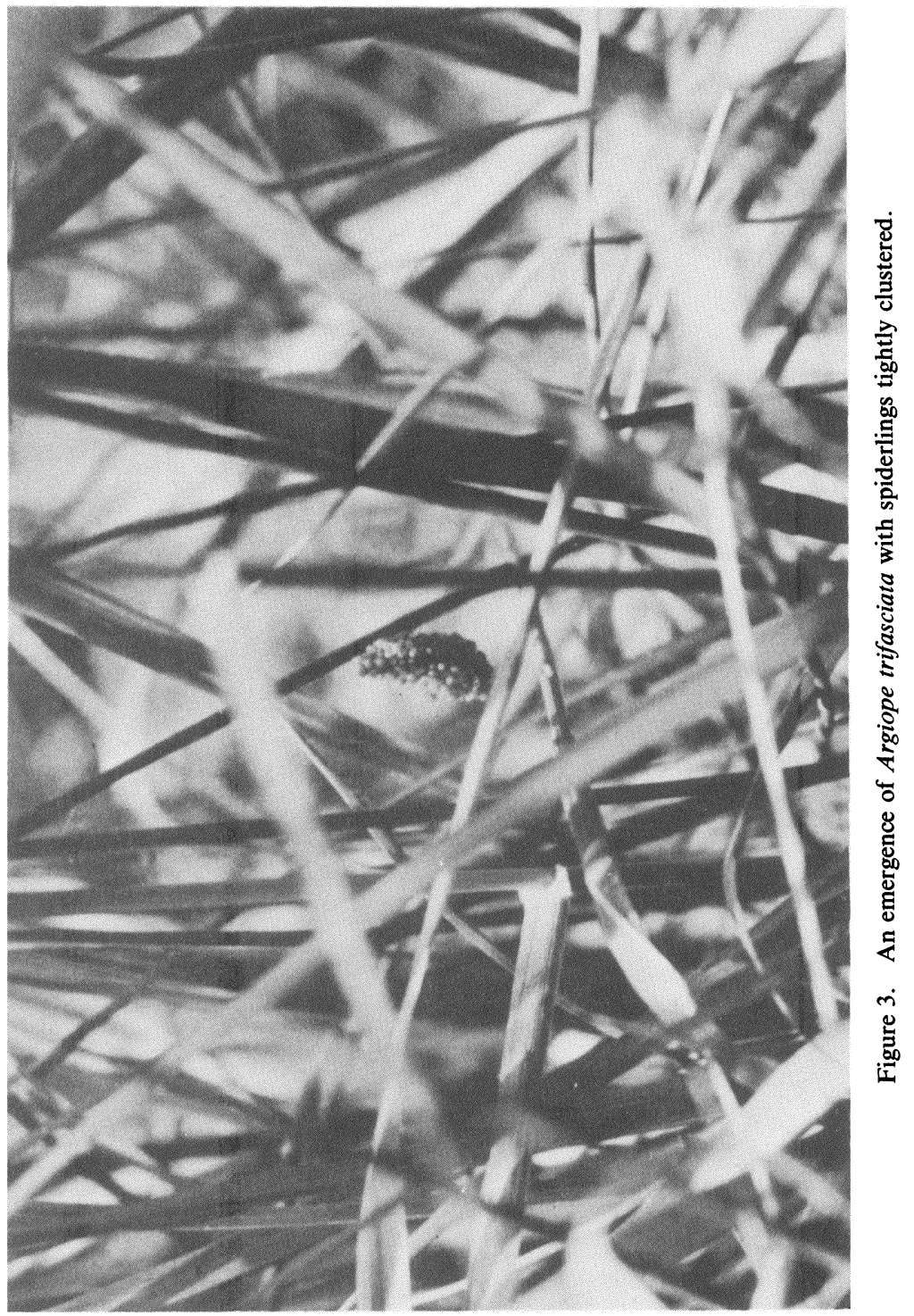


when their body temperatures were above $26^{\circ} \mathrm{C}$, and their preferred range was virtually identical to that of Argiope trifasciata (Figure 5). Seventy-four percent of $A$. aurantia spiderlings dispersed when their body temperatures were between $33^{\circ}$ and $38^{\circ} \mathrm{C}$. A disturbance (gust of wind, striking the vegetation to which the communal tangle is attached, striking the tangle itself, and fanning the cluster of spiders directly) resulted in spiderling movement on the tangle. The nature of the disturbance seems to be vibrational and subsequent movement by spiderlings on the interlocking mass of silk threads of the communal tangle appeared to reinforce the initial disturbance. When a sufficient disturbance occurred and spider body temperatures were $26^{\circ} \mathrm{C}$ or higher, the spiderlings climbed to the top of any available object, usually vegetation. Spiderlings followed one another in mass to the top of a promontory where they prepared to disperse. Neither disturbance nor elevated temperature by itself was sufficient to trigger climbing behavior of $A$. trifasciata (Figure 1). By monitoring spiderling body temperatures on the communal tangle (spiderlings of eight Argiope trifasciata egg sacs in 1975), it was apparent that the spiderlings often experienced temperatures within their observed dispersal range $\left(26^{\circ}-42^{\circ} \mathrm{C}\right)$, but did not disperse. This was also evident by the time of residency on communal tangles during sunny periods (Table 1). Striking the vegetation near the tangle or fanning the cluster of spiderlings during times when body temperatures equalled or exceeded $26^{\circ} \mathrm{C}$ invariably induced climbing. Similar stimulation at body temperatures of less than $26^{\circ} \mathrm{C}$ failed to produce climbing behavior.

In April 1976, two additional clusters of $A$. trifasciata spiderlings were tested. Even when body temperatures exceeded $26^{\circ} \mathrm{C}$ and a vibratory stimulus was applied, these spiderlings could not be induced to climb and disperse. While these findings might simply be abberations or due to some genetic differences between populations between the two years, or to some microclimatic variables which were not examined, it seems likely that developmental differences between the spiderlings which emerged in May and those in April may account for the observed difference in behavior.

$A$. trifasciata overwintered as eggs and the active spiderlings did not develop until April (Tolbert, 1976). A difference of as much as one month to six weeks in the developmental age of spiderlings could influence behavior. It is possible that the older spiderlings would be more prone to dispersal behavior than younger spider- 


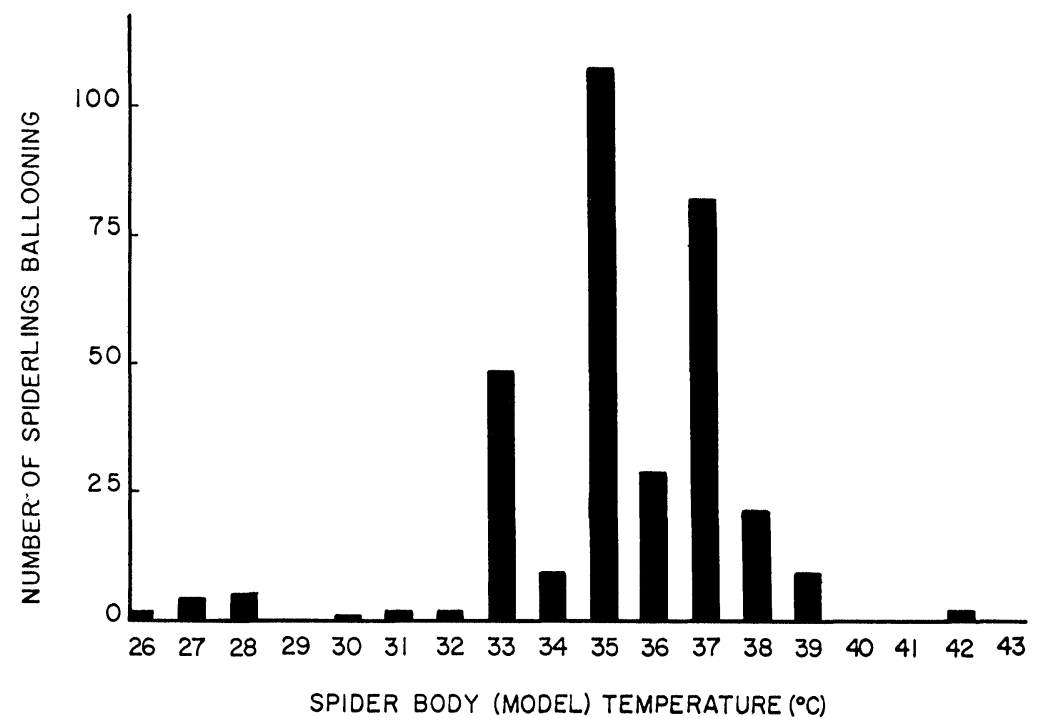

Figure 4. Number of Argiope trifasciata ballooning as a function of body (model) temperature.

lings. Residence time by spiderlings on communal tangles was somewhat longer in early May than in late May (Table 1). Computing mean residence time (in days) from the data in Table 1, reveals 7.5 days for the spiderlings emerging on 10 May, 8 days for 11 May, 5 days for 14 May, 2.3 days for 19 May, and 4 days for 22 May.

Richter (1970) has stated that dispersal by spiders normally occurs on days that are unusually warm and calm for the time of year. In the same study, he demonstrated that a wolf spider, Pardosa purbeckenis F. O. B. Cambridge exhibited aeronautic behavior when laboratory air temperatures were varied between $18^{\circ}$ and $34^{\circ} \mathrm{C}$. The percentages of aeronautic behavior for each temperature range he used (which I calculated from his Table 4) were $6.9 \%\left(18-19^{\circ} \mathrm{C}\right), 34.8 \%\left(28-29^{\circ} \mathrm{C}\right)$ and $36.4 \%\left(33-34^{\circ} \mathrm{C}\right)$. In 1975 , 20 of the $24 \mathrm{~A}$. trifasciata spiderling masses dispersed on sunny days (see Table 1). Thus, it appears that dispersal in Argiope is influenced by climatogical factors, and in particular temperature. In addition to these findings, Duffey (1966) in monitoring winter 


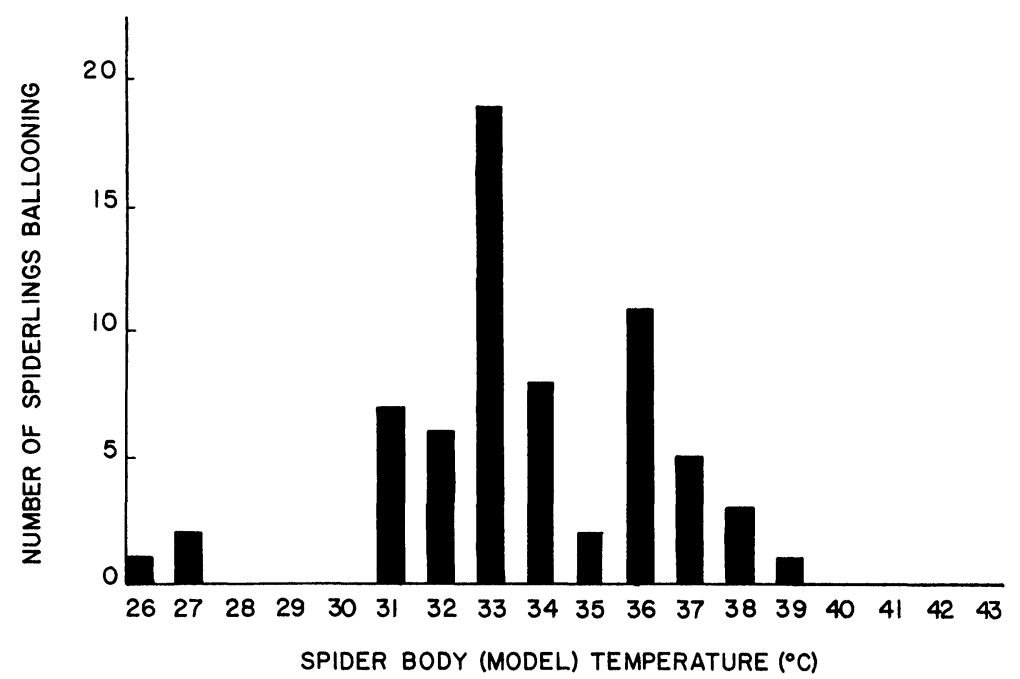

Figure 5. Number of Argiope aurantia ballooning as a function of body (model) temperature.

dispersal of linyphiids, indicated that increasing litter temperatures were partially responsible for increased aerial dispersal by members of this litter-dwelling spider family. Gypsy moth (Porthetria dispar $\mathrm{L}$.) larvae ascend trees preparatory to aerial dispersal when ambient air temperatures are between $15.6^{\circ} \mathrm{C}\left(50^{\circ} \mathrm{F}\right)$ and $29.4^{\circ} \mathrm{C}$ $\left(85^{\circ} \mathrm{F}\right)$. These larvae, however, have black dorsal surfaces and their body temperatures when exposed to direct sunlight can easily exceed air temperatures (McManus, 1973). Thus, the aerial dispersal of some spider and insect species is influenced by temperature.

\section{Aeronautic Behavior}

In preparation for dispersal, individuals may adopt either a "tiptoe" posture, as defined by Richter (1970) or hang suspended from a dragline from which they become airborne (Figure 1). The tiptoe stance, which is widely employed by lycosid spiders (Richter, 1970), results when the spider depresses the cephalothorax toward the substrate and elevates the abdomen. Silk lines are then exuded from the spinnerets. Multiple lines of ballooning. silk were often 
Table 1. Argiope trifasciata residency on communal tangles and associated weather conditions during May, 1975. S = sunny, $\mathrm{PC}=$ partly cloudy, $\mathrm{C}=$ cloudy, $\mathrm{X}=$ presence, $\mathrm{Y}=$ dispersal on same day as emergence. Dispersal occurred on last day spiderlings were present.

$\begin{array}{lcccccccccccccccc}\text { May } & 10 & 11 & 12 & 13 & 14 & 15 & 16 & 17 & 18 & 19 & 20 & 21 & 22 & 23 & 24 & 25 \\ \text { Weather } & \text { S } & \text { S } & \text { PC } & \text { S } & \text { S } & \text { C } & \text { C } & \text { C } & \text { S } & \text { S } & \text { S } & \text { S } & \text { S } & \text { PC } & \text { PC } & \text { S }\end{array}$

Egg sac

number

5

6

11

12

13

14

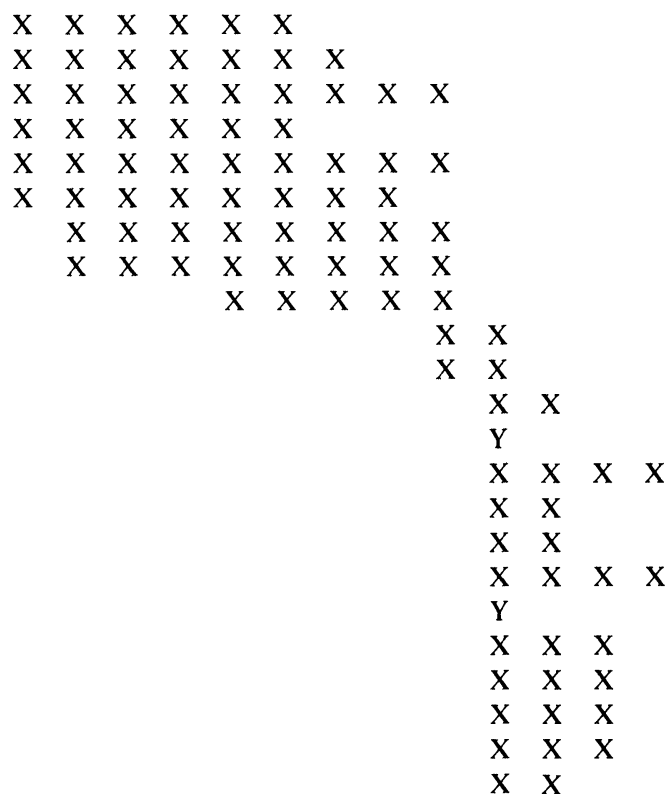

$\begin{array}{llll}X & X & X & X\end{array}$

observed and there appeared to be four to six lines, but the exact number was not determined. Spiderlings also dispersed directly from silk threads. They dropped on a dragline, cut it and while suspended and holding this thread by leg pairs I and II, let out ballooning silk as before, until they became airborne.

Spiderlings, as a rule, became airborne during relatively calm periods with a preferred windspeed for dispersal of approximately $0.5 \mathrm{~m} / \mathrm{sec}$. (Figure 6). During gusty periods spiderlings either did not exhibit tip-toe postures at all or if in that posture, returned to 


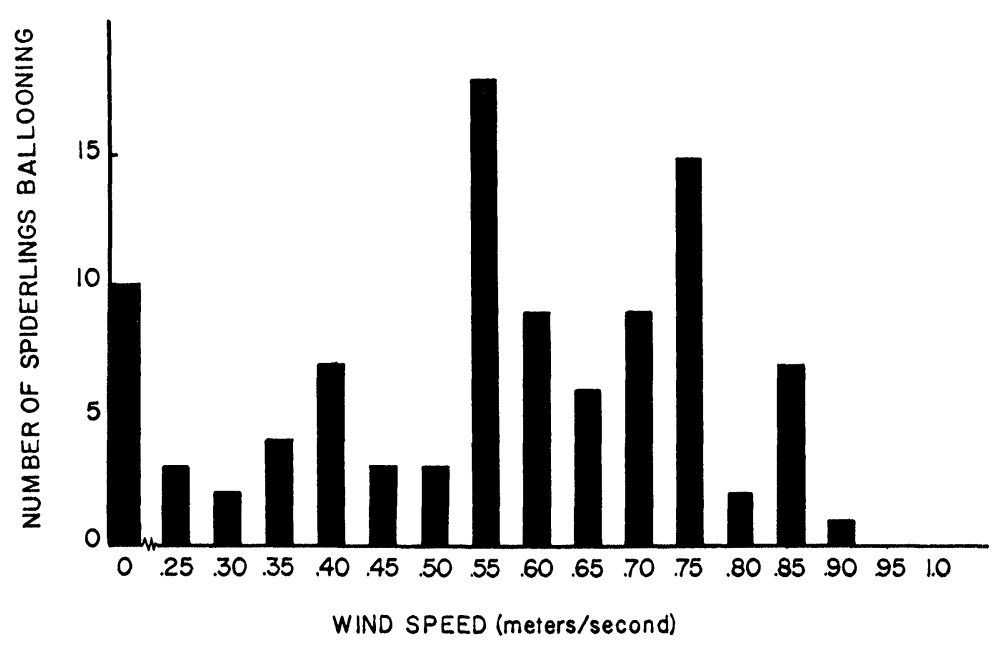

Figure 6. Number of Argiope trifasciata ballooning as a function of windspeed.

a normal resting attitude. Spiderlings did not disperse at windspeeds of greater than $0.9 \mathrm{~m} / \mathrm{sec}$. (Figure 6). Richter (1971) showed that Pardosa purbeckensis had preferred windspeeds for dispersal which were related to their body sizes; larger spiders preferred greater windspeeds. All size classes, however, preferred wind velocities between 0.35 and $1.70 \mathrm{~m} / \mathrm{sec}$. These values exceed those observed for Argiope trifasciata, which is a slightly larger spider than Pardosa purbeckensis. From their study of spiders on Frisian Island (the Netherlands) Van Wingerden and Vugts (1974) concluded that aeronautic behavior ceased when the wind velocity at $2 \mathrm{~m}$ above the substrate exceeded $3.0 \mathrm{~m} / \mathrm{sec}$. They also found in the same study that unstable air masses near the ground and at dispersal height served as stimuli to aeronautic behaviour. Disturbances (wind gusts) apparently function in a similar fashion for Argiope trifasciata.

After a spiderling becomes airborne it will travel on wind currents until deposited at a potential web location. The spiderling may then build a web, or move a short distance from the deposition site (perhaps searching for a site of better potential for web construction), and then build a web (Figure 1). It might also reballoon with or without "searching behavior." Data on the relative 
frequencies of these behaviors are scarce. Approximately 20 argiopids were observed to reballoon during the course of the study, some as many as six times with the majority $(90 \%)$ of these observed reballooning bouts occurring when the spiderlings were in close proximity to the egg sac. It is possible that a minimum time or distance requirement must be achieved before the spiderling has satisfied a "ballooning drive." It might also reflect investigator error since spiderlings which drop into dense vegetation are difficult to detect and the probability of finding individuals must decrease with distance from the egg sac (with decreased density of spiderlings). Nevertheless, multiple ballooning bouts probably function to increase emigration from a given area (which would tend to lessen competition for food, web sites or other resources if such resources are in short supply). Since Argiope spp. actively select web sites (Enders, 1972, 1973), it is probable that areas judged unsuitable by the spiderlings can be quickly and easily abandoned via reballooning. This finding is consistent with the predictions of Doyle's (1975) habitat selection model. Organisms which encounter coarse-grained (patchy) environments, as Argiope do, can improve fitness by selecting habitat types yielding highest survivorship. Riechert (1973) demonstrated that a desert agelenid spider, Agelenopsis aperta (Gertsch) improved the quality of its web sites by successive relocation in better web sites. A. aperta walked rather than ballooned to new web sites, however. Riechert and Tracy (1975) produced a model of reproductive success that demonstrates a thirteen fold advantage in fecundity of spiders living in good versus poor web sites. Habitat selection and differential survival of Argiope spp. is an area worthy of additional research.

One or more days may elapse after the spiderling locates a web site before it actually builds a web there. This is based on two sets of observations. First, spiderlings discovered in the field without webs and checked later the same day had not built webs $(\mathrm{N}=5)$. Only spiderlings found early in the morning and thus not recently dispersed are considered here. Two of these individuals built webs one day later; one built two days later. Second, even during the height of Argiope trifasciata aerial dispersal (mid-May) few spiderlings were observed to have webs. Possibly the spiderlings were adjusting from a colonial, passive existence to one of active predation. Whatever the reason(s), considerable mortality is suffered during this period (Tolbert, 1976). Spiderlings would certainly be 
vulnerable to predation, especially since they do not have the protection a web affords (Tolbert, 1975). Some spiderlings probably starve during this time also (Tolbert, 1976).

Spiderlings underwent a radical change in behavior toward conspecifics after dispersing from the communal tangle. As long as the spiderlings were on the communal tangle they were completely tolerant of one another and during hot sunny periods clustered very closely together. However, after a spiderling constructed an orb web it attacked and ate any prey that contacted the web. Littermates were invariably attacked and treated as prey items when they encountered or were placed on conspecific's orb web. However, it is unnecessary for spiderlings of either Argiope species to engage in aerial dispersal before building an orb web. I have successfully reared both species in the laboratory after removing them from egg sacs. After building their first orb web and without the benefit of living on or building a communal tangle or engaging in aerial dispersal, Argiope spiderlings still attacked and killed littermates placed on their orb webs.

Although Enders (1972) indicated he has observed unsuccessful ballooning attempts by mid-instar Argiope aurantia, my observations indicate that only the emergent (first instar) disperses aerially.

\section{Summary}

Although both species are capable of all the behaviors in the ethogram (Figure 1), Argiope aurantia, possibly by virtue of their higher, more exposed egg sac locations, generally dispersed shortly after emergence from the egg sac. Argiope trifasciata produced communal tangles and engaged in preaeronautic behaviors on these structures before dispersing.

In 1975, both spider species ballooned when their estimated body temperature exceeded $26^{\circ} \mathrm{C}$, with most dispersal occurring when body temperatures were between $33^{\circ}$ and $38^{\circ} \mathrm{C}$. A vibrational stimulus occurring when spider body temperatures are above $26^{\circ} \mathrm{C}$ resulted in climbing behavior by the mass spiderlings on the communal tangle. Upon reaching the top of a promontory they either became airborne from that point or dropped on a dragline and ballooned from that position. Spiderlings ballooned at relatively low wind speeds $(0.5 \mathrm{~m} / \mathrm{s})$. Multiple ballooning bouts were observed for some individuals. It is hypothesized that aerial dispersal serves to rapidly space spiderlings over available habitats such that 
overcrowding is minimized. Aerial dispersal would also allow successional species such as $A$. trifasciata and $A$. aurantia to colonize newly opened, ephemeral habitats.

\section{ACKNOWLEDGMENTS}

I gratefully acknowledge the assistance of James Tanner, Gordon Burghardt, Charles Pless and David Etnier who ably served on my doctoral committee. I am especially grateful to Susan Riechert, my committee chairperson. I acknowledge the financial support of the National Science Foundation, Grant For Doctoral Dissertation Improvement (BMS 74-17602) and the Graduate Program in Ecology of the University of Tennessee.

\section{REFERENCES}

BRISTOWE, W. S.

1939. The comity of spiders, Vol. I. Iohnson Reprint Corp., New York.

DOYLE, R. W.

1975. Settlement of planktonic larvae: A theory of habitat selection in varying environments. Amer. Natur. 109: 113-126.

DUFFEY, E.

1956. Aerial dispersal in a known spider population. J. Anim. Ecol. 25: 85-111.

ENDERS, F.

1972. Web-site selection by Argiope aurantia Lucas and other orb weaving spiders (Araneidae). Unpublished Ph.D. dissertation, N. C. State University.

ENDERS, F.

1973. Selection of habitat by the spider Argiope aurantia Lucas (Araneidae). Amer. Midl. Natur. 90(1): 47-55.

EMERTON, J. H.

1908. Autumn flights of spiders. Psyche 15: 121.

GEIGER, R.

1965. The climate near the ground. Harvard Univ. Press, Cambridge.

GERTSCH, W. J.

1949. American spiders. D. Van Nostrand Co., Inc., Princeton.

KASTON, B. J.

1972. How to know the spiders, 2nd edition. W. C. Brown Co., Dubuque. McManus, M. L.

1973. The role of behavior in the dispersal of newly hatched Gypsy Moth Larvae. USDA Forest Service Research paper NE-267, 10p.

NISHIKI, S.

1966. On the aerial migration of spiders. Acta Arachnologica 20(1): 24-34 (Japanese with an English Summary). 
RICHTER, C. J. J.

1970. Aerial dispersal in relation to habitat in eight wolf spider species (Pardosa, Araneae, Lycosidae). Oecologia 5: 200-214.

RICHTER, C. J. J.

1971. Some aspects of aerial dispersal in different populations of Wolf Spiders, with particular reference to Pardosa amentata (Araneae, Lycosidae). Misc. Pap. Landb. Hogesch. Wageningen 8: 77-88.

RIECHERT, S. E.

1976. Web site selection in a desert spider, Agelenopsis aperta (Gertsch). Oikos 27: 311-315.

RiECHERT, S. E. AND R. TRACY.

1975. A model relating web-site characteristic to spider reproductive success. Ecology 56: 265-284.

TOLBERT, W. W.

1975. Predator avoidance behaviors and web defensive structures in the orb weavers Argiope aurantia and Argiope trifasciata (Araneae, Araneidae). Psyche 82: 29-52.

TOLBERT, W. W.

1976. Population dynamics of the orb weaving spiders Argiope trifasciata and Argiope aurantia (Araneae, Araneidae): Density changes associated with mortality, natality and migrations. Unpubl. Ph.D. dissertation, U. of Tennessee.

VALERIO, C. E.

1975. A unique case of mutalism. Amer. Natur. 109: 235-238.

VAN Wingerden, W. K. R. E. AND H. F. VugTs.

1974. Factors influencing aeronautic behavior of spiders, Bull. Brit. Arach. Soc. 3: 6-10. 

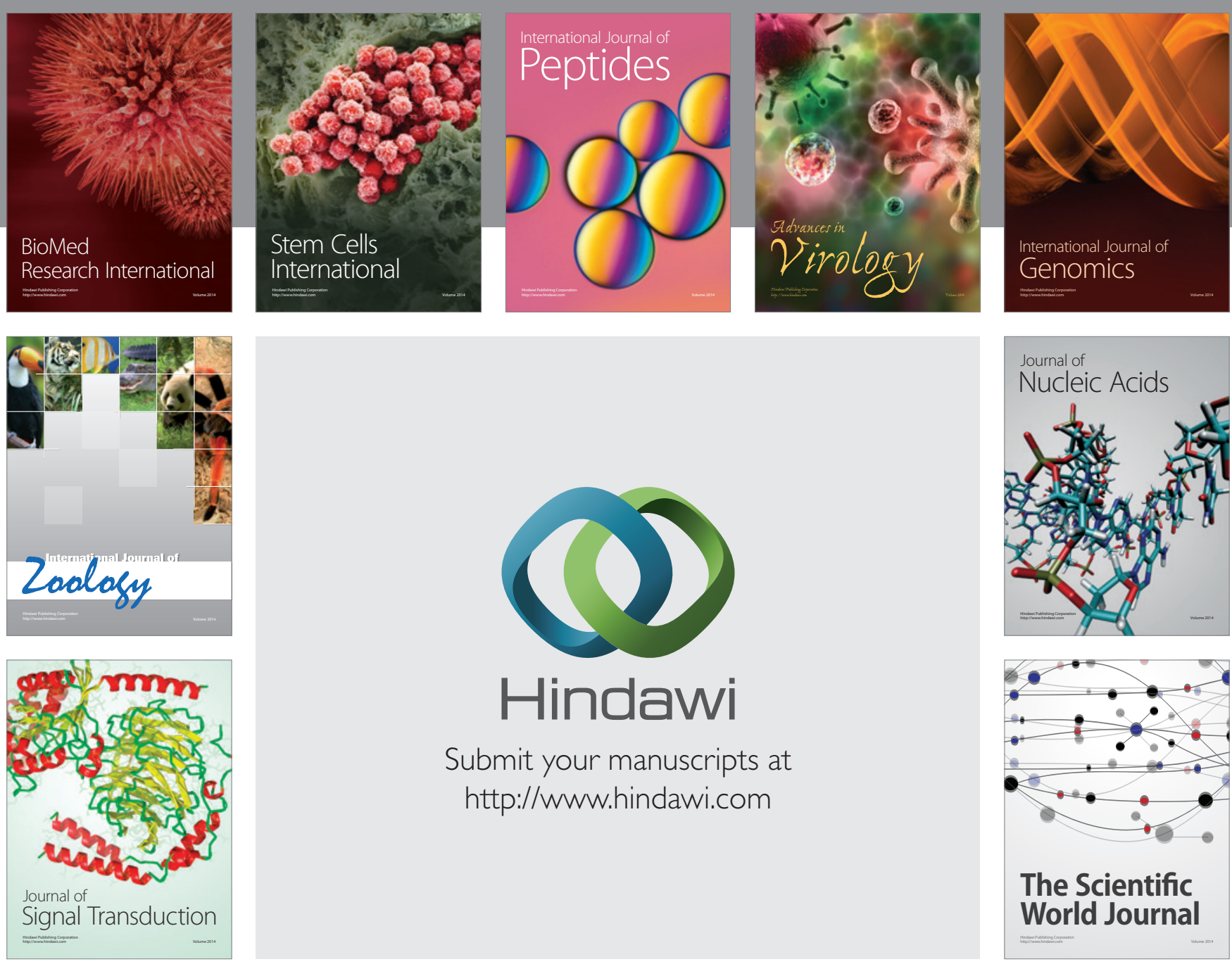

Submit your manuscripts at

http://www.hindawi.com
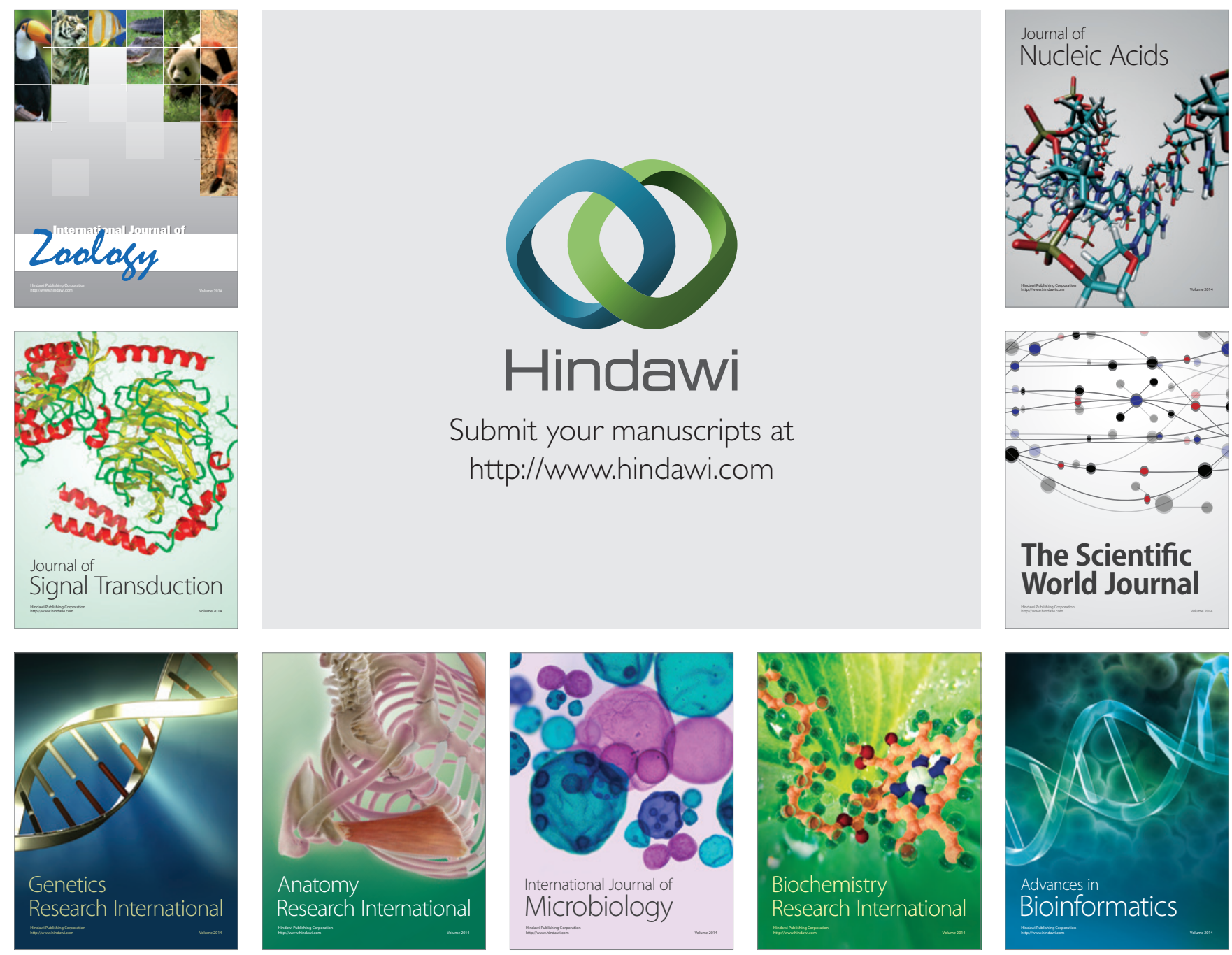

The Scientific World Journal
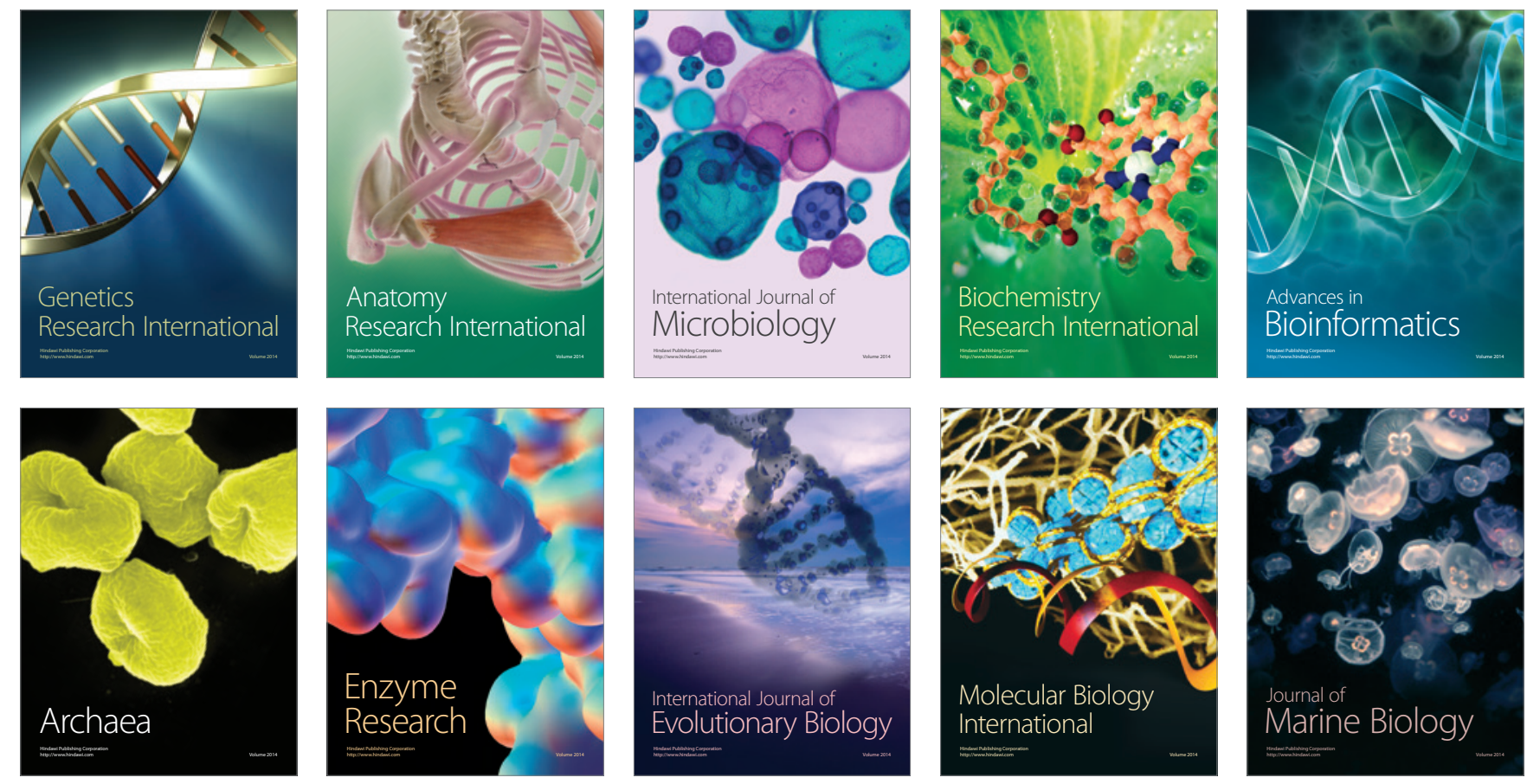